THE Food Research Institute of Stanford University has prepared two maps of Africa south of the Sahara, including Madagascar but excluding the Union of South Africa, showing administrative divisions down to the cercle or district level or the equivalent in states within the tropical belt. One is a simple outline map with no lettering; the other is the same base map with the divisions numbered for identification from an accompanying mimeographed list of names. The scale is $I: 12,000,000$, and the frames measure about $19 \times 24$ inches. The administrative divisions are based on the latest official or semi-official sources available to the Institute, dates of which are indicated in the list of names. The outline map is printed by offset on paper of a quality suitable for additional ink work for publication. The identification map is reproduced by the direct-print (black line) process. Copies may be obtained from the Food Research Institute, Stanford University, Stanford, California, at 35 cents each for the outline map and 50 cents for the identification map and list of names, plus is cents on each order for postage and handling.

\title{
African Studies at Johns Hopkins University, Washington
}

Dr. Vernon McKaY, formerly Deputy Director of the Office of Dependent Area Affairs in the United States Department of State, has been appointed Professor of African Studies in the School of Advanced International Studies of the Johns Hopkins University, 1906 Florida Avenue, N.W., Washington, D.C. Open only to university graduates, the school specializes in current political and economic problems of international significance. Under Dr. McKay's direction, it intends to expand its courses on Africa.

\section{International Congress of Linguists}

THE 8th International Congress of Linguists is to be held in Oslo from 5 to 9 August 1957. The chief topics with which the Congress will be concerned are : the contribution of typological studies to historical comparative linguistics; the importance of distribution versus other criteria in linguistic analysis; the contribution of new techniques of acoustical phonetics to linguistics; the extent to which meaning can be said to be structured. During sectional meetings other more specialized aspects of linguistic study will be discussed, including principles of dictionary definition, preparation of teaching material, new electrical equipment, native informant reaction in linguistic analysis, \&c. The Congress is open only to linguists invited by the Organizing Committee; all inquiries and correspondence should be addressed to the Secretary: Miss Eva Sivertsen, Kirkevein 98 A III, Oslo NV, Norway.

\section{Margaret Wrong Memorial Awards}

The Silver Medal, 1959, was awarded to a Nigerian writer, Mr. D. O. FAGUNwA, for his book in Yoruba, Irinkerindo Ninu Igbo Elegbeje (1954, Thomas Nelson \& Sons, Ltd.). A prize of $£_{20}$ was awarded to Mr. SANnuo LazAre, Cameroun Français, for a manuscript in French, 'Mon pays d'Hier'.

Entries for the Silver Medal, 1956, must be received before 28 February 1957.

Since the arrangements that have hitherto governed the award of the Margaret Wrong Medal and Prize have not, in the opinion of the Committee, satisfactorily achieved the objects of the Memorial Fund, new terms and conditions will come into force from January I958. From that date the Committee proposes to award annually a Medal and money prize to an African from any part of Africa south of the Sahara, who has given outstanding services to literature in the year previous to the award.

Full particulars may be obtained from:

The Hon. Secretary, Margaret Wrong Memorial Fund,

2 Eaton Gate, London, S.W. I. 